\title{
Серебро как катионирующий агент при идентификации аминокислот методом МАЛДИ-МС
}

\author{
Кузнецова Е.С., Пыцкий И.С., Буряк А.К. \\ ФГБУ Науки Институт физической химии и электрохимии имени А.Н. Фрумкина РАН, Москва
}

Поступила в редакцию 21.02.2018 г.

DOI: https://doi.org/10.17308/sorpchrom.2018.18/505

Проведено систематическое исследование ионизации аминокислот методом MALDI. Показано, что получение высокоинтенсивных пиков аминокислот в данном методе возможно только при использовании высокоразвитых поверхностей, например, саж различного типа. Для более эффективного катионирования аминокислот предложено использовать при ионизации соли серебра. Показано, что при работе подобным методом образуются высоскоинтенсивные пики катионированных серебром аминокислот. Кроме этого, показано, что хлорид серебра при ионизации аминокислот выполняет роль матрицы и стабилизирует крупные кластерные агломераты аминокислот в плазме над поверхностью нержавеющей стали.

Ключевые слова: масс-спектрометрия, хлорид серебра, кластерообразование, катионирование, аминокислоты, ионные кластеры.

\section{Silver as a cationizing agent in the identification of amino acids by the MALDI-MS method}

\author{
Kuznetsova E.S., Pytskii I.S., Buryak A.K. \\ Institute of Physical Chemistry and electrochemistry RAS, Moscow
}

\begin{abstract}
A systematic study of the ionization of amino acids by the MALDI method was carried out. One of the important areas of research in modern science is the study of physicochemical processes during ionization in various ways A Bruker Ultraflex mass spectrometer (Bruker, Germany) equipped with a nitrogen laser $(\lambda=337 \mathrm{~nm})$ was used to study the cluster formation. To increase the efficiency of ionization and information content of mass spectra, silver halides were synthesized in aqueous solutions by mixing solutions of silver nitrate and the corresponding potassium halide. Amino acids were applied to the surface of stainless steel from a water-acetonitrile solution. In the mass spectrum, a wide range of different cluster ions of silver chloride is seen and the first clusters with a charged center on the cluster Ag3. Threonine can be identified by an adduct with silver having an intensity of peaks of about $5000 \mathrm{abs}$. units and the signal-to-noise ratio is more than 500, which is 1.5 orders of magnitude better than for ionization without the use of silver chloride. It is shown that the production of high-intensity peaks of amino acids only with the use of highly developed surfaces, for example, carbon blacks of various types in this method is possible. For more effective cationization of amino acids, it has been proposed to use silver ions for ionization. It was shown that high-intensity peaks of amino-cationized silver are formed by this method. In addition, it was shown that silver chloride ionizing amino acids serves as a matrix and stabilizes large cluster agglomerates of amino acids in plasma above the surface of stainless steel.
\end{abstract}

Keywords: mass-spectrometry, silver chloride, cluster foundation, cationization, amino acids, ion clusters 


\section{Введение}

Одним из важных направлений исследований в современной науке является изучение физико-химических процессов при ионизации различными способами [12]. Одним из популярных методов подобных исследований является матричноактивированная лазерная десорбция/ионизация (МАЛДИ). Наиболее полно эти процессы описаны в [3]. Кроме этого, авторами проведён ряд исследований по изучению ионизации различных солей и органических соединений [4,5]. В настоящей работе авторы приводят результаты своих исследований ионизации аминокислот в присутствии солей серебра. В указанных выше работах показано, что при ионизации аминокислоты методом МАЛДИ могут образовываться катионированные натрием и калием аддукты с аминокислотами. Предположительно серебро также способно катионировать аминокислоты. Кроме этого, серебро имеет два изотопа (107 и 109), что облегчает поиск аминокислот благодаря уникальному изотопному распределению аддукта с серебром. Соединения серебра легко ионизируются и образуют кластерные ионы. Поэтому будет проверена возможность увеличения чувствительности идентификации аминокислот по аддуктам с серебром.

\section{Эксперимент}

Для проведения исследования кластерообразования использовали массспектрометр Bruker Ultraflex (Bruker, Германия), оборудованные азотным лазером $(\lambda=337$ нм). Частота импульсов варьировалась от 5 до 20 Гц, количество выстрелов от 10 до 100, мощность одного импульса - от 5 до 100\%. В качестве модельных объектов исследования использовали набор аминокислот: треонин, фенилаланин, аспарагин, гистидин и пролин (Sigma Aldrich, США). В предыдущих работах авторов было показано значи- тельное увеличение эффективности ионизации этих и других аминокислот при нанесении их на различные углеродные сорбенты [6-7]. Пробоподготовка с использованием углеродных сорбентов часто бывает сложной из-за неравномерности нанесения и, как следствие, неравномерности кристаллизации аналита. Актуально максимальное упрощение пробоподготовки для мониторинга аминокислот на поверхности. Самым простым способом ионизации является нанесение образца непосредственно на поверхность рабочей плашки. Ионизация аминокислот таким способом значительно затруднена. Для увеличения эффективности ионизации и информативности масс-спектров использовали галогениды серебра, синтезированные в водных растворах смешением растворов нитрата серебра и соответствующего галогенида калия (Реахим, Россия). Аминокислоты наносили на поверхность нержавеющей стали из водно-ацетонитрильного раствора (1:1 по объёму). Вода milli-Q, ацетонитрил JT Baker, США). В раствор галогенидов серебра перед нанесе- нием на поверхность добавляли ацетонитрил в эквивалентном водному раствору ко- личестве. Сначала наносили раствор аминокислоты, сушили на воздухе в течение 10 минут, затем наносили суспензию галогенида серебра.

\section{Обсуждение результатов}

На рис. 1 приведён масс-спектр гистидина в режиме регистрации положительных ионов. Наблюдаются три пика небольшой интенсивности: 155.8 Да - протонированный ион гистидина, 177.8 - гистидин+Na и 193.8 - гистидин+К.

Из спектра видно, что идентифицировать гистидин с высокой чувствительностью невозможно. При добавлении хлорида серебра к раствору гистидина получен масс-спектр, изображённый на рис. 2.

Кузнецова и др. / Сорбционные и хроматографические процессы. 2018. Т. 18. № 2 
Из масс-спектра видно, что помимо катионированного серебром гистидина $\left(\mathrm{M}+\mathrm{Ag}^{+}\right)$образуются высокоинтенсивные пики аддуктов с натрием и калием на порядок превышающие аналогичные на рисунке 1 . Кроме этого на рисунке 2 видно образование сложных кластерных ионов с участием одной и двух молекул хлорида натрия, которые стабилизируют аминокислоту в виде её димера. Таким образом, гистидин можно идентифицировать по шести различным пикам (4 катионированных аддукта и 2 кластерных иона).

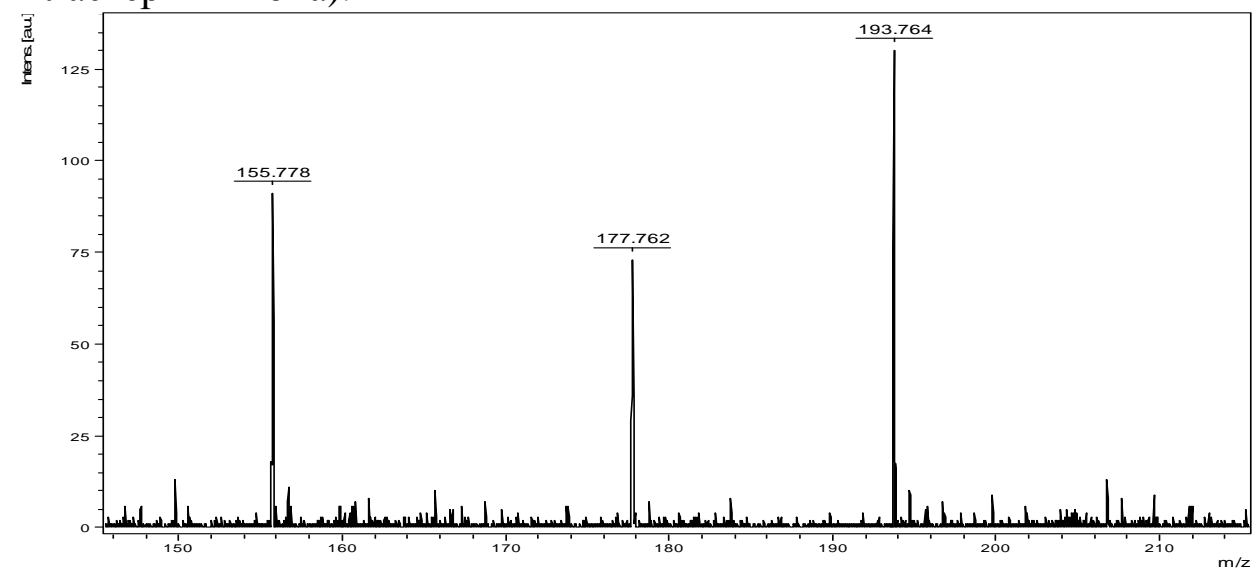

Рис. 1. Масс-спектр гистидина в режиме регистрации положительных ионов.

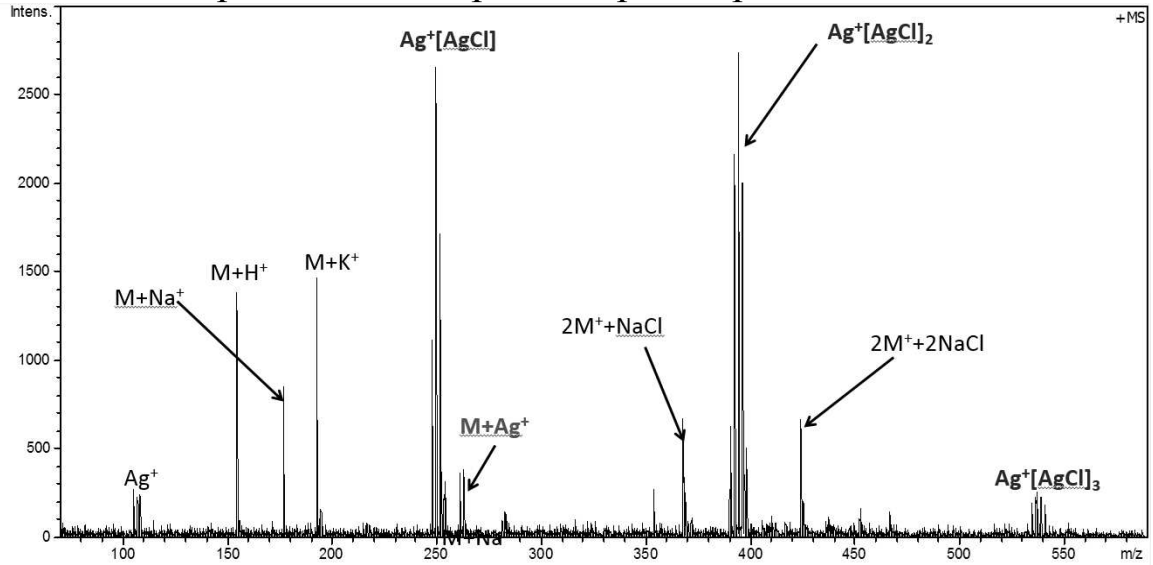

Рис. 2. Масс-спектр гистидина в режиме регистрации положительных ионов при добавлении суспензии хлорида серебра.

При исследовании линейной аминокислоты треонина был получен массспектр, изображённый на рис. 3.

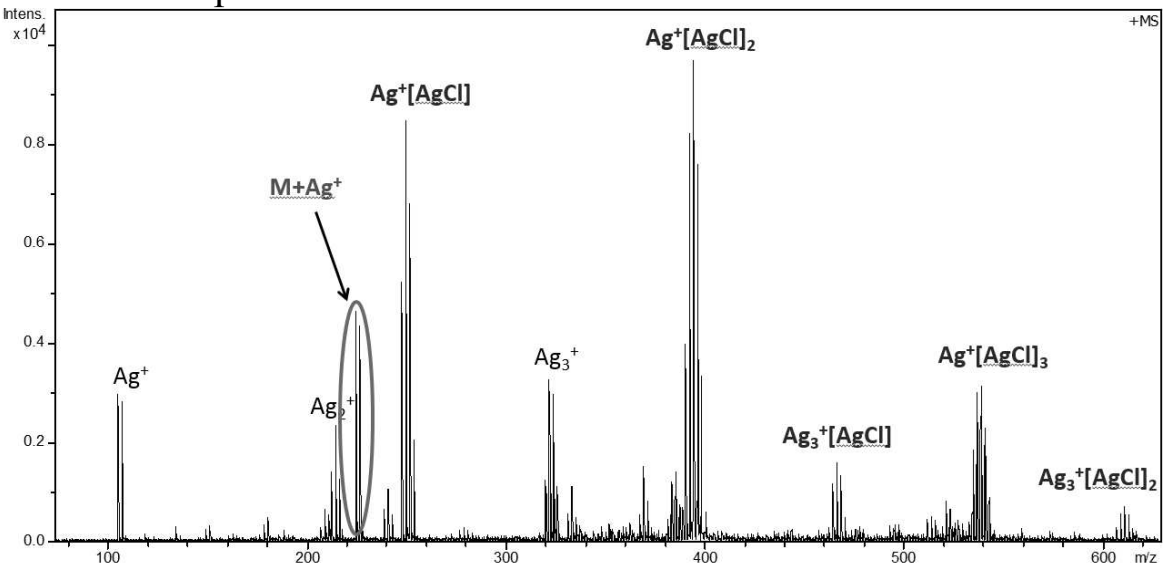

Рис. 3. Масс-спектр треонина в режиме регистрации положительных ионов при добавлении суспензии хлорида серебра. 
Из масс-спектра видно, что треонин возможно идентифицировать по аддукту с серебром имеющему интенсивность пиков около 5000 абс. ед. и отношение сигнал/шум более 500, что на полтора порядка лучше, чем при ионизации без использования хлорида серебра. Также в масс-спектре виден широкий набор различных кластерных ионов хлорида серебра и впервые обнаруженные кластеры с заряженным центром на кластере $\mathrm{Ag}_{3}$. Механизм подобных процессов является темой для последующих исследований. Полные результаты исследований приведены в таблице 1.

Таблица 1. Сравнение результатов исследования аминокислот на поверхности нержавеющей стали и с добавлением хлорида серебра.

\begin{tabular}{|c|c|c|}
\hline Аминокислота & $\begin{array}{c}\text { Без добавления хлорида } \\
\text { серебра }\end{array}$ & $\begin{array}{c}\text { С добавлением хлорида се- } \\
\text { ребра (серебро/аминокислота } \\
=1: 100)\end{array}$ \\
\hline Гистидин & 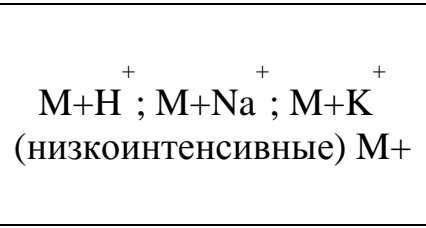 & $\begin{array}{c}\text { Рост интенсивности пиков } \\
\text { более, чем на порядок+ } \\
\mathrm{M}+\mathrm{Ag}^{+} \\
2 \mathrm{M}^{+}+\mathrm{NaCl}+\mathrm{H}^{+} \\
2 \mathrm{M}^{+}+2 \mathrm{NaCl}+\mathrm{H}^{+} \\
\end{array}$ \\
\hline Аспарагин & Нет пиков & $\mathrm{M}+\mathrm{Ag}^{+}(\mathrm{S} / \mathrm{N} \sim 120-140)$ \\
\hline Пролин & $\begin{array}{c}\mathrm{M}+\mathrm{H}^{+} ; \mathrm{M}+\mathrm{Na}{ }^{+} ; \mathrm{M}+\mathrm{K}^{+} \\
(\text {низкоинтенсивные) }\end{array}$ & $\begin{array}{c}\text { Рост интенсивности пиков }+ \\
\mathrm{M}+\mathrm{Ag}^{+} \\
3 \mathrm{M}^{+}+\mathrm{Na}^{+} \\
3 \mathrm{M}^{+}+\mathrm{K}^{+}\end{array}$ \\
\hline Треонин & Нет пиков & $\begin{array}{c}\mathrm{M}+\mathrm{H}^{+} ; \mathrm{M}+\mathrm{Na}^{+} ; \mathrm{M}+\mathrm{K}^{+} \\
\mathrm{M}+\mathrm{Ag}^{+}(\mathrm{S} / \mathrm{N}>1000)\end{array}$ \\
\hline Фенилаланин & $\begin{array}{c}\mathrm{M}+\mathrm{H}^{+} ; \mathrm{M}+\mathrm{Na}^{+} ; \mathrm{M}+\mathrm{K}^{+} \\
(\text {низкоинтенсивные) }\end{array}$ & $\begin{array}{c}\text { Рост интенсивности пиков на } \\
\left.1,5 \text { порядка (кроме } \mathrm{M}+\mathrm{H}^{+}+\right)+ \\
\mathrm{M}+\mathrm{Ag}^{+}(\mathrm{S} / \mathrm{N}>1000) \\
2 \mathrm{M}+\mathrm{Na}^{+} ; 2 \mathrm{M}+\mathrm{K}^{+}\end{array}$ \\
\hline
\end{tabular}

\section{Заключение}

Как следует из табл. 1, использование серебра в качестве катионирующего агента при мониторинге аминокислот и исследовании процессов поверхностной ионизации в значительной мере оправдано. Помимо высокоинтенстивного пика $\mathrm{M}+\mathrm{Ag}^{+}$ в масс-спектрах некоторых аминокислот также появляется несколько дополнительных кластерных ионов аминокислот с солями натрия и калия, что характеризует хлорид серебра, как эффективную матрицу для МАЛДИ-масс-спектрометрии, которая эффектвно перераспределяет УФ-излучение лазера и тем самым предотвращает распад крупных кластерных агломератов, образующихся в плазме при ионизации.

\section{Список литературы/References}

1. Lin L., Weng C., Chen Q., Nuclear Instruments and Methods in Physics Research Section B: Beam Interactions with Materials and Atoms, Vol. 414, No 1, pp. 79-83.

2. Kozlov A.N., Konovalov V.S. Communications in Nonlinear Science and Numerical Simulation Vol. 51, pp. 169-179

3. Murakami K., Sato A., Hashimoto K., Fujino T., Chemical Physics, Vol. 419, pp. 37-43.
4. Goncharova I.S.; Pytskii I.S.; Buryak A.K., Protection of metals and physical chemistry of surfaces, 2014, Vol. 50, No 6, pp. 723-732.

5. Pytskii I.S.; Buryak A.K., Protection of metals and physical chemistry of surfaces, 2014, Vol. 50, No 1, pp. 121-125.

6. Kuznetsova E.S., Buryak A.K., Protection Metals, 2011, Vol 47, No 6, pp. 586-593. 
7. Kuznetsova E.S., Uleanov A.V., Buryak A.K., J. of Phys. Chem.. 2009, Vol. 83, No 4,

Кузнецова Елена Сергеевна - старший научный сотрудник лаборатории синтеза и исследования сорбентов, к.х.н. Институт физической химии и электрохимии имени А.Н. Фрумкина РАН, Москва

Пыцкий Иван Сергеевич - старший научный сотрудник лаборатории физико- химических основ хроматографии и хромато- массспектрометрии, к.х.н. Институт физиче- ской химии и электрохимии имени А.Н. Фрумкина РАН, Москва

Буряк Алексей Константинович - заведующий лабораторией физико-химических основ хроматографии и хромато-масс- спектрометрии, проф, д.х.н. Институт физи- ческой химии и электрохимии имени А.Н. Фрумкина РАН, Москва pp. 638-642.

Kuznetsova Elena S. - PhD (chemistry), laboratory of synthesis and investigation of sorbents, Institute of Physical chemistry and electrochemistry, Moscow.

Pytskii Ivan S. - PhD (chemistry), laboratory of physical-chemical basics of chromatography and chromato-mass-spectrometry, Institute of Physical chemistry and electrochemistry, Moscow. E-mail: ivanpic4586@gmail.com

Buryak Alexey K. - prof., grand $\mathrm{PhD}$ (chemistry), laboratory of physical-chemical basics of chromatography and chromato-mass-spectrometry Institute of Physical chemistry and electrochemistry, Moscow 